\title{
Computer Science Does Matter
}

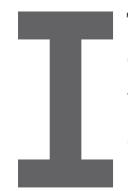

T WAS DISAPPOINTING that two competent computer scientists-Matthias Felleisen and Shiram Krishnamurthi-took such a narrow view in their Viewpoint "Why Computer Science Doesn't Matter" (July 2009). For them programming is apparently the essence of computer science, at its best when coupled with mathematics practice; therefore the science and engineering don't matter in the contest for young minds in high school.

They wrote, but did not justify, that "programming is our field's single most valuable skill" (what about the ability to abstract?); that graphics is "frosting" (really?); that the "three Rs" are the driving force in the $\mathrm{K}-12$ curriculum (a view no longer shared by leading educators); and that leading CS educators want to emphasize engineering and science while marginalizing programming (say again?). This odd amalgam of unfounded assumptions led them to the untenable conclusion that hiding computing in a mathematics curriculum strengthens CS in high schools.

Their extended example of "imaginative programming" illustrates a genuinely creative way to make high school mathematics more engaging. It also seemed to be an argument for more CS, not less; CS and computational thinking can provide students valuable concepts and frameworks for understanding complex subjects while making courses more interesting to them.

I agree with them that the ETS decision to abolish AP tests in CS was deplorable, and we should all be working to reverse it.

Education leaders have long known that the best way to get $\mathrm{K}-12$ schools to teach a particular subject is for universities to require that their students have prior education in that subject. This strategy has been particularly effective in California, which has a dominant, respected university system. If we want entering freshman to have more rigorous preparation in computing, we need to work on our respective universities to require it. In some cases, it may be as simple as instituting the requirement in one's own department.

Felleisen's and Krishnamurthi's exhortation to hide behind mathematics makes no sense. We should instead be proactively making the case not only for CS qua CS but for CS as a powerful conceptual tool in a variety of endeavors.

They were right to call attention to the early stages of the university curriculum. Ignoring them, CS will never attract the students it wants. Here, because the definition of CS comes to the fore, consider two principles: Insisting on a narrow definition of a field is not a sound idea in a period of growth and discovery, as it limits innovation. And we know from experience and research that the best way to motivate students to learn the fundamentals is to show them how they are used. A broad definition and relevant examples help all students, especially those who have decided to not major in computing.

Peter A. Freeman, Atlanta, GA

Matthias Felleisen and Shiram Krishnamurthi (July 2009) referred to my and Andrew McGettrick's “The Profession of IT" column "Recentering Computer Science” (Nov. 2005), claiming we sought to marginalize "our field's most valuable skill (programming)." That is not what we sought or accomplished. We wrote because we were deeply concerned about an external view of the field that marginalized us because it deeply misunderstands what we mean by programming. We speculated that the public perception that $\mathrm{CS}=$ programming, coupled with the narrow public view of the definition of "programming," cast the entire field in a poor light. We wrote that programming is an essential core practice that won't disappear. We suggested that recentering our own thinking (making it less focused on programming while including more engineering and science) would help build a much stronger curriculum and public image.

Peter J. Denning (past president of ACM), Monterey, CA

\section{Authors Respond:}

Freeman correctly recognizes that we called for additional CS education, not less. He can certainly try to convince schools to introduce computing but will likely meet the response that it's already provided in the courses that teach Word and Excel. This is indeed what we've learned from our 14 years in the trenches of outreach.

Our vision offers students a strong foundation for abstraction, engineering, and science-with compelling content from the bottom up, not by fiat imposed from the top down.

Matthia Felleisen, Boston

Shriram Krishnamurthi, Providence, RI

\section{ACM Content Wants to Be Free}

Addressing the question of why ACM doesn't adopt the open-access model for its publications in his Editor's Letter "Open, Closed, or Clopen Access?" (July 2009), Moshe Y. Vardi wrote that "'free' is not a sound business model."

Though he was rebutting the conventional wisdom that "information wants to be free," here the word "free" meant freedom, not price. Freedom is not a sound business model. It is not a business model at all but rather a mode of social interaction that human beings value and aspire to achieve.

Moreover, ACM is not a conventional business enterprise, describing itself, right on the Communications masthead, as "the world's largest educational and scientific computing society." As such, its mission is not to generate profits by implementing business models, sound or unsound, but to promote the open exchange of ideas. This means ACM publications should be, as defined by the Budapest Open Access Initiative (http://www.soros.org/openaccess/read.shtml), available to the public, so everyone is able to "read, download, copy, distribute, 
print, search, or link to the full texts of these articles, or use them for any other lawful purpose, without financial, legal, or technical barriers other than those inseparable from gaining access to the Internet itself." Vardi, to his credit, is a signer of the Initiative. I urge him to reconsider its implications for ACM journals.

His more general point was that the status quo should be good enough, since the price of ACM's publications is, in his words, "very reasonable." He invited readers to consult their librarians for confirmation. My librarian, Kevin Engel of the Kistle Science Library at Grinnell College, says that the prices charged for ACM publications are roughly comparable to those of other professional organizations, perhaps not quite as outrageous as those of, say, the American Chemical Society, though somewhat more outrageous than the American Psychological Association.

However, Engel also says that ACM stands out as the only professional organization that views the print version of its publications as its main profit center and hence refuses to offer an online-only subscription bundle, putting many researchers and students at a disadvantage.

As a signer of the Budapest Initiative, I strongly prefer open access to ACM journals for everyone. Even if ACM is unwilling to take such a step, we could move incrementally in this general direction by unbundling its subscriptions and making the online editions of its publications separately available for purchase.

John David Stone, Grinnell, IA

I'd like to thank Moshe Y. Vardi for his thoughtful analysis of open access (July 2009) and offer a few additional points. (My employer, O'Reilly Media, provides technical information in the form of books and other media in both open and closed forms; this comment does not necessarily represent the views of O'Reilly Media.) The most valuable benefit of providing open access to publications is it allows us to be "part of the conversation" in vibrant and productive online forums. ACM publications are widely cited; I just checked my own articles and blogs over the past few years and found I referred to Communications
16 times. Were the articles easier to search, read, and link to on the Web, they would play an even more important role in online discussions, as they do in professional publications. Reader comments would further enhance the value of the content.

However, this would not solve Vardi's concern over the cost of editing and publishing. He wrote that the prices charged for ACM journals not only cover the cost of their publication (an impressive achievement in itself) but yield a surplus that supports other ACM activities (truly commendable). I don't blame ACM for sticking to its partly closed model.

An alternative, if ACM were to go open, would be to subsidize publications through increased dues or other charges. I'm sure it would alter the calculation for ACM members (particularly students) when deciding whether to join for the first time or renew their memberships each year and might require new forms of fundraising. It's certainly common for organizations to ask members and donors to pay for development of information otherwise offered free to the world. If these publications represent the core offering to ACM members, the strategy is risky.

Andy Oram, Cambridge, MA

I'd like to propose yet another business model for the ACM Digital Library that blends both sides of the open vs. closed access debate, per Moshe Y. Vardi (July 2009). I agree that high-quality science publishing bears unavoidable costs even for electronic-only journals readers should pay for. But scientific papers should be shared free of charge with the largest audience possible. As a teacher, I must often explain basic algorithms and data structures by citing original pioneering papers. Because these "old" papers are still under copyright, students cannot freely and securely access them in digital libraries. They get only a limited view of their full technical coverage, getting the main aspects of highly cited papers while missing the full scope of the techniques being covered.

ACM should consider making available (for free) a set of highly rated CS papers from the Digital Library. This would offer students the historical papers that forged the science in the first place, letting them in turn explore the functionalities of the Digital Library and inspiring their future interest in being subscribers. One way to do so might be to offer a free Education $\mathrm{Li}^{-}$ brary as a subset of the Digital Library.

Frank Nielsen, Paris, France

\section{ACM Responds:}

Concerning Stone's comments, please know that ACM does offer online-only subscriptions; a library need not buy a print package in order to subscribe to the Digital Library. In fact, most ACM library customers today belong to consortia for which the basic package is online-only access to the Digital Library with one free print package included; additional print packages are available to every member of a consortium, though few opt to buy them. Meanwhile, print long ago ceased to be ACM's "main profit center"; revenue from digital offerings far exceeds revenue from print. In any case, it is increasingly difficult to make a financial case for continuing print. For a number of publications, the print side must be subsidized, mainly to satisfy a dwindling set of library customers. Finally, ACM does offer electronic-only subscriptions to individual titles. Members and non-members alike are able to buy print-only subscriptions, electroniconly subscriptions, or print+electronic subscriptions to individual titles.

Bernard Rous, ACM Electronic Pub-

lishing Program Director, New York

Communications welcomes your opinion. To submit a Letter to the Editor, please limit your comments to 500 words or less and send to letters@cacm.acm.org.

(C) 2009 ACM 0001-0782/09/0900 $\$ 10.00$

Coming Next Month in

COMMUNICATIONS

A View of the Parallel Computing Landscape

An Interview with

David E. Shaw

Probing the Biomolecular

Landscape

Smoothed Analysis

Plus, the latest news in shape-shifting devices, e-health records, and supercomputing, data management, and analysis. 